\title{
A community-based survey on COVID-19 Knowledge, Attitudes, Practices and Vaccination Hesitance in Moshi, Kilimanjaro Region, Northern Tanzania
}

\section{Jaffu Chilongola ( $\sim$ j.chilongola@kcri.ac.tz)}

Department of Medical Biochemistry and Molecular Biology, Faculty of Medicine Kilimanjaro Christian Medical University College, P.O Box 2240, Moshi Tanzania https://orcid.org/0000-0003-2997-6747

\section{Kevin Rwegoshola}

Department of Medical Biochemistry and Molecular Biology, Faculty of Medicine Kilimanjaro Christian Medical University College, P.O Box 2240, Moshi Tanzania

\section{Hadija Semvua}

Kilimanjaro Clinical Research Institute, P.O Box 2236, Moshi, Tanzania

\section{Edith Kwigizile}

Department of Social Sciences, Faculty of Education and Social Sciences, Stefano Moshi Memorial University College, P. O. Box 881, Moshi, Tanzania

\section{Research Article}

Keywords: COVID-19, knowledge, attitudes, practices, vaccination hesitancy

Posted Date: February 7th, 2022

DOI: https://doi.org/10.21203/rs.3.rs-1327017/v1

License: (a) (i) This work is licensed under a Creative Commons Attribution 4.0 International License. Read Full License 


\section{Abstract}

Background: The development of COVID-19 vaccinations has reignited optimism in many cultures devastated by the pandemic's tremendous loss of lives and livelihoods. Vaccination hesitancy $(\mathrm{VH})$ is a critical and growing international problem in the global effort to manage the COVID-19 pandemic. To successfully handle VH concerns, it is necessary to understand the levels of knowledge, attitudes, and behaviours on COVID-19. The purpose of this study was to collect data on COVID-19 knowledge, behaviours, and attitudes as an illness, as well as COVID-19 vaccine.

Methods: In October 2021, a cross-sectional research with 232 participants was undertaken. A standardized interviewer-administered questionnaire was used to collect data. The majority of respondents in the present survey heard about COVID-19 between January and March 2020. Social media, news media, and news papers are the most effective sources of information on COVID-19, reaching $34.48 \%$ of the population. Basic COVID-19 knowledge was reported to be moderate. Nearly half of the respondents $(48.3 \%$ ) thought SARSCOV-2 was man-made, while $36.21 \%$ were unsure. Good preventive behaviours were indicated by $49.14 \%$ of subjects. Overall, we find that around $65 \%$ of people are reluctant to get vaccinated against COVID-19. Male gender, low education, and occupation (teachers, health care workers, and students) were shown to be more hesitant about vaccination. In this study, healthcare workers (HCWs) were averse to get COVID-19 vaccine. The reasons for vaccination hesitation were "unknown safety" of the vaccines $(17.4 \%)$ and "unknown long term consequences" of the vaccines $(18.97 \%)$. Almost a third $(27.59 \%)$ of those interviewed said they had no intention of being vaccinated.

Conclusion: We report moderate knowledge on COVID-19, as well as effective preventive practices, but negative attitudes regarding COVID-19 vaccination, resulting in low vaccination rates of $6.9 \%$. Misinformation regarding COVID-19 appears to play a key role in vaccination reluctance.

\section{Introduction}

SARS-CoV-2 infection, also known as new corona virus illness (COVID-19), was first diagnosed in Wuhan, China, in December 2019, and the World Health Organization proclaimed COVID-19 a pandemic in less than three months. By early May 2020, 3.3 million people had been infected in 213 countries, resulting in 238,628 deaths. The COVID-19 outbreak has resulted in numerous cases of illness and mortality around the world, and the unavailability of a COVID-19 vaccination has played a significant role in the high morbidity and mortality rates. Vaccines for COVID-19 are now being rolled out and made available in a number of countries. Vaccines' importance as one of the most significant successes in the fight against communicable diseases has been recognized for long $[1,2]$.

Due to the very efficient nature of vaccination programs on the African continent against vaccinepreventable diseases as a result of high and sustainable uptake, Africa has historically reported impressive reductions in mortality and morbidity from infectious diseases [2,3]. As a result, vaccination adoption is crucial for personal health, protecting vulnerable people, improving socioeconomic life, and 
achieving population health and safety through immunity. The development of COVID-19 vaccines has rekindled hope in many societies that have been devastated by the pandemic's massive loss of lives and livelihoods. Nonetheless, as the acquisition and distribution of COVID-19 vaccines gain traction, tensions and challenges have surfaced and are developing in tandem. Supply issues, vaccine nationalism, inequitable vaccine distribution and access both within and between nations, and COVID-19 vaccine hesitancy $(\mathrm{VH})$ are only a few examples [4-7]. When vaccination services are available and accessible, vaccine hesitancy refers to a refusal to get immunizations. It is not only widespread and inaccurate, but it is also extremely contagious [8]. The effectiveness and safety of vaccine campaigns to control COVID-19 are not the only factors to consider.

The general public's and healthcare personnel' acceptance of vaccines appears to play a critical part in the pandemic's successful management. VH and rejection appear to be a rising problem, according to recent continental and global surveys [9-12]. The highest acceptance rates among adults were found in Ecuador (97.0\%), Malaysia (94.3\%), Indonesia (93.3\%), and China (93.3\%), according to a comprehensive evaluation of global COVID19 acceptance rates from 33 different nations (91.3\%). Kuwait (23.6\%), Jordan (28.4\%), Italy (53.7\%), Russia (54.9\%), Poland (56.3\%), the United States (56.9\%), and France (58.9\%) had the lowest COVID-19 vaccination acceptance rates[13]. In a separate large community-based study on COVID-19 vaccine hesitancy in the US, it was found out that $22 \%$ of the respondents were hesitant to take these vaccines if they were available[14]. Although data on acceptance rates appears to be scarce, published studies reveal that acceptance rates range from $27.7 \%$ in the Democratic Republic of the Congo to $78.1 \%$ in Israel 13]. In the Middle East, Russia, Africa, and various European nations, low rates of COVID-19 vaccine uptake have been recorded $[3,9,10,13,15]$.

Tanzania was one of the countries to embrace the vaccination strategy, receiving the first consignment of $1,058,450$ doses of Johnson \& Johnson COVID-19 vaccines in July 2021, and 1,065,600 doses of Sinopharm vaccines supplied by the Chinese government via the COVAX facility in early October 2021. Despite all of these initiatives to battle the disease through vaccine, according to recent report, only $1.5 \%$ of Tanzanians have been fully vaccinated [https://ourworldindata.org/covid-vaccinations? country=OWID_WRL], which makes the campaign for covid19 vaccination in Tanzania a challenge. $\mathrm{VH}$ poses a serious challenge in the global attempt to control the COVID-19 pandemic at a time when the virus is undergoing fast alterations linked with successive waves of outbreaks.

VH has already been documented African nations following the introduction of new vaccines. Tanzanians, like many other Africans, were regarded at danger of under-immunization prior to the COVID19 pandemic, with lower levels of routine vaccine uptake and trust in vaccination [16-18]. Furthermore, these populations may be more prone to COVID-19 vaccine disinformation, particularly due to anti-vaccination buzz, as well as a lack of reliable information due to language hurdles and social marginalization. In Tanzania, where the first strategy for reducing COVID19 was a mixed model that included hand sanitization, mask wearing, social distancing, and the use of indigenous medicines without lock-down, an understanding of community members' hesitance is crucial. The purpose of this study was to gather information on COVID19 knowledge, practices, and attitudes as a disease and 
COVID19 vaccination in one of the regions most affected by COVID19 morbidity and mortality: the Kilimanjaro region in Northern Tanzania.

\section{Methodology}

\section{Study Design, Site and Study Population}

A cross-sectional study was conducted in October 2021. Individuals who visited their relatives admitted or undergoing medical care at Kilimanjaro Christian Medical Centre, were asked to participate in responding to structured questions regarding COVID19.

\section{Study Procedure}

Due to the country's imposed measures to control COVID19 resistance at the time of data collection, we opted to use interview individuals who visited the mentioned health care facilities. This option was easy, time convenient but also compliant to COVID19 control restrictions of social distancing. Participants who were mentally or physically capable of giving consent, willing to participate, and above the age of 18 were included, but those who were unwilling to participate were not interviewed. Due to the absence of similar studies on COVID19 in the study area, the sample size was determined to be 232 using a single population proportion formula based on the assumption that the probability of having poor knowledge, attitude, and preventive practice towards COVID 19 was $50.0 \%$ percent, with a $95.0 \%$ confidence interval and a $5 \%$ margin of error.

\section{Data collection and data collection tool}

The information was gathered using a standardized interviewer-administered questionnaire that had been pre-tested. Socio-demographic factors, awareness, and KAP regarding COVID-19 and COVID-19 vaccination were included in the questionnaire. The questionnaire was completed using "True/False" and "Yes/No" options and an additional "I don't know" option. A correct or positive answer received 1 point, whereas an incorrect/negative or unknown response received 0 points.

\section{Scoring and definitions of dependent Variables}

\section{COVID-19 knowledge assessment}

To measure participants' knowledge of covid-19, a total of 23 items were employed. Each correct answer received a score of one, while incorrect answers received a score of zero. Using Bloom's cut-off point, participants' total knowledge was classified as excellent if their score was between 80 and $100 \%$ (2318.4), moderate if their score was between 60 and 79 percent (18.17-13.8), and low if their score was less than 60 percent (13.8)[19]

Assessment of attitude towards health seeking 
Three items were used to examine participants' attitudes regarding obtaining medical help. A right response received a score of one, while a wrong answer received a score of zero. Bloom's cut-off point was used to describe the attitude toward health seeking as positive if the score was between 80 and 100 percent (3-2.4), neutral if it was between 60 and 79 percent (1.8-2.37), and negative if it was less than 60 percent (1.8) [20].

\section{Prevention practice assessment}

Six factors were used to measure prevention practice against covid-19. A right response received a score of one, while a wrong answer received a score of zero. Using Bloom's cut-off point, participants' overall preventative practice against covid-19 was classified as excellent if the score was between 80 and 100 percent (6-4.8), moderate if the score was between 60 and 79 percent (4.74-3.6), and bad if the score was less than 60 percent (13.6) [21].

\section{Assessment of attitude towards COVID-19 vaccine}

Three questions were used to examine people's attitudes regarding the COVID-19 vaccination. A right response received a score of one while a wrong answer received a score of zero. The attitude toward the COVID-19 vaccination was classified as positive if the score was between 80 and 100 percent (4-3.2), neutral if the score was between 60 and 79 percent (3.16-2.4), and negative if the score was less than 60 percent (2.4). 2018 [20]

\section{Quality assurance}

The reliability of the knowledge, attitude, and practice questionnaires was assessed, and the Cronbach's alpha values were $0.71,0.78$, and 0.76 , respectively, indicating acceptable internal consistency. Four research scientists were involved in data collection. The whole data gathering procedure was overseen and controlled by the senior supervisors. The completed questionnaires were checked by the supervisors for completeness and consistency of replies. Before the actual data collecting began, the questionnaires were revised as needed.

\section{Data analysis and Processing}

After completing the questionnaires, they were exported to Microsoft Excel 2016 for cleaning and coding. The cleaned data was transferred to STATA version 15.1 for analysis. To summarize categorical data, frequencies and proportions were employed. Bloom's cut-off of $80 \%$ was utilized to assess if respondents had adequate knowledge ( $80 \%)$, indicating a favourable outcome. Chi squared test was conducted to evaluate the respondent factors and responses (components) related with limited knowledge and poor practice. With a $p$ value of 0.05 , the test revealed the strength of the relationship between risk variables and knowledge and practice. Finally, the information was arranged and classified.

\section{Study Variables}




\section{Independent Variables}

Demographic details which include sex, age, academic qualification, highest level of education, work environment, and sources of information on COVID-19. Specific items were specific questions for determination of knowledge, attitudes and practices regarding CPOVID-19 and vaccination hesitancy.

\section{Results}

\section{Social demographics characteristics of participants}

Socio demographic characteristics of respondents are summarized in Table 1. A total of 232 participants were interviewed. The median age of respondents was 33 (IQR: 25, 45). One hundred and sixty eight (72.41\%) of the participants were male, while $36.21 \%$ (84) had secondary school education. Compared to other occupations, majority of participants $(24.14 \%)$ were traders $46.55 \%$ (108). One hundred and sixty eight $(72.41 \%)$ of these participants did not suffer income reduction due to COVID-19 pandemic.

Table 1: Social- Demographic characteristics of the participants $\mathrm{N}=232$ 


\begin{tabular}{llll}
\hline Variable & $\mathbf{n}$ & $\%$ \\
\hline Age category & & \\
\hline $15-24$ & 48 & 20.69 \\
\hline $25-34$ & 80 & 34.48 \\
\hline $35+$ & 104 & 44.83 \\
\hline Gender & & \\
\hline Male & 168 & 72.41 \\
\hline Female & 64 & 27.59 \\
\hline Level of education & & \\
\hline Primary education & 80 & 34.48 \\
\hline Secondary education & 84 & 36.21 \\
\hline Vocational education & 28 & 12.07 \\
\hline University education & 40 & 17.24 \\
\hline Occupational & & \\
\hline Teacher & 16 & 6.9 \\
\hline Peasant & 48 & 20.69 \\
\hline Trader & 56 & 24.14 \\
\hline Doctor/Nurse & 4 & 1.72 \\
\hline Driver & 8 & 3.45 \\
\hline Student & 40 & 17.24 \\
\hline Others & 60 & 25.86 \\
\hline
\end{tabular}

\section{Working environment}

\begin{tabular}{lll} 
Hospital & 16 & 6.9 \\
\hline School & 50 & 21.55 \\
\hline Market & 52 & 22.41 \\
\hline Town & 46 & 19.83 \\
\hline Home & 28 & 12.07 \\
\hline Other & 40 & 17.24
\end{tabular}

\section{Level of crowdedness}




\begin{tabular}{llll} 
Very crowded & 88 & 37.93 \\
\hline Moderately crowded & 108 & 46.55 \\
\hline Least crowded & 16 & 6.9 \\
\hline Isolated & 20 & 8.62 \\
\hline Income reduction due to COVID-19 pandemic & & \\
\hline No & 168 & 72.41 \\
\hline Yes, I lost my job/had salary reduction due to quarantine period & 4 & 1.72 \\
\hline Yes, I lost my job/had salary reduction due to restriction & 60 & 25.86 \\
\hline Concerned of contracting and infecting COVID-19 & & \\
\hline Not at all concerned & 76 & 32.76 \\
\hline A little concerned & 72 & 31.03 \\
\hline Somewhat concerned & 16 & 6.9 \\
\hline Very concerned & 68 & 28.31
\end{tabular}

\section{Source of information on COVID-19}

Figure 1 shows that most of the participants (55.17\%) had heard about COVID-19 for the first time between January and March 2020. The combination of social media, news media and news paper was the strongest source of information regarding COVID-19, reaching and $34.48 \%$ of participants with newspapers alone contributing $32.76 \%$ as the strongest source of information (Fig 2).

\section{COVID-19 knowledge assessment}

Table 2 displays the knowledge results for COVID-19. The majority of participants (65.52\%) had a moderate understanding of COVID-19. In terms of primary COVID-19 symptoms, "coughing" was cited by 224 (96.55\%) of the participants, followed by "touching" and "handshaking," which were both noted by 212 (91.38\%) of the questioned people. Other symptoms cited by 208 (89.66 percent) and 204 (87.93\%), respectively, were "runny nose" and "fever." When asked if SARS CoV-2, the cause of COVID-19, was a man-made or natural virus, $112(48.3 \%)$ of participants answered it was man-made, compared to 36 (15.52\%) and 84 (36.21\%) who replied "natural" and "do not know," respectively. Majority (77.59\%) of participants cited China as the origin of the virus that causes COVID-19. Overall, interviewed participants displayed "moderate" knowledge on COVID-19.

Table 2: COVID-19 knowledge assessment $\mathrm{N}=232$ 
1. Is SARS Cov2 natural or man-made?

$\begin{array}{lcc}\text { Natural } & 36 & 15.52 \\ \text { Man made } & 112 & 48.28 \\ \text { I don't know } & 84 & 36.21\end{array}$

2. Where did SARS Cov2 originate from?

\begin{tabular}{lll} 
America & 16 & 6.9 \\
\hline Australia & - & - \\
\hline Europe & 28 & 12.07 \\
\hline China & 180 & 77.59 \\
\hline Africa & - & - \\
\hline India & - & - \\
\hline I don't know & 8 & 3.45
\end{tabular}

3. Is SARS Cov2 a zoonotic disease (transmitted from Animals to Humans)?

$\begin{array}{lll}\text { No } & 92 & 39.66 \\ \text { Yes } & 52 & 22.41 \\ \text { I don't know } & 88 & 37.93\end{array}$

4. How is COVID-19 transmitted?

Coughing

\begin{tabular}{|lll|}
\hline No & 4 & 1.72 \\
\hline Yes & 224 & 96.55 \\
\hline I don't know & 4 & 1.72 \\
\hline Hugging & & \\
\hline No & 20 & 8.62 \\
\hline Yes & 200 & 86.21 \\
\hline I don't know & 12 & 5.17 \\
\hline Touching & & \\
\hline No & 8 & 3.45 \\
\hline Yes & 212 & 91.38 \\
\hline
\end{tabular}




\begin{tabular}{|c|c|c|}
\hline I don't know & 12 & 5.17 \\
\hline \multicolumn{3}{|l|}{ Handshake } \\
\hline No & 8 & 3.45 \\
\hline Yes & 212 & 91.38 \\
\hline I don't know & 8 & 5.17 \\
\hline \multicolumn{3}{|c|}{ Blood transfusion } \\
\hline No & 84 & 36.21 \\
\hline Yes & 112 & 48.28 \\
\hline I don't know & 12 & 5.17 \\
\hline \multicolumn{3}{|l|}{ Sex intercourse* } \\
\hline No & 84 & 36.84 \\
\hline Yes & 116 & 50.88 \\
\hline I don't know & 28 & 12.28 \\
\hline \multicolumn{3}{|c|}{ Contaminated food items } \\
\hline No & 76 & 32.76 \\
\hline Yes & 116 & 50 \\
\hline I don't know & 40 & 17.24 \\
\hline \multicolumn{3}{|c|}{ 5. What are the common symptoms of Covid-19? } \\
\hline \multicolumn{3}{|l|}{ Fever } \\
\hline Associated & 204 & 87.93 \\
\hline Not associated & 20 & 8.62 \\
\hline Don't know & 8 & 3.45 \\
\hline \multicolumn{3}{|l|}{ Headache } \\
\hline Associated & 204 & 87.93 \\
\hline Not associated & 20 & 8.62 \\
\hline Don't know & 8 & 3.45 \\
\hline \multicolumn{3}{|c|}{ Myalgia (Muscle pain) } \\
\hline Associated & 180 & 77.59 \\
\hline Not associated & 20 & 8.62 \\
\hline
\end{tabular}




\begin{tabular}{|c|c|c|}
\hline Don't know & 32 & 13.79 \\
\hline \multicolumn{3}{|l|}{ Smell } \\
\hline Associated & 192 & 82.76 \\
\hline Not associated & 12 & 5.17 \\
\hline Don't now & 28 & 12.07 \\
\hline \multicolumn{3}{|l|}{ Sore throat } \\
\hline Associated & 188 & 81.03 \\
\hline Not associated & 12 & 5.17 \\
\hline Don't know & 32 & 13.79 \\
\hline \multicolumn{3}{|l|}{ Runny nose } \\
\hline Associated & 208 & 89.66 \\
\hline Not associated & 16 & 6.9 \\
\hline Don't know & 8 & 3.45 \\
\hline \multicolumn{3}{|l|}{ Diarrhea } \\
\hline Associated & 100 & 43.10 \\
\hline Not associated & 68 & 29.31 \\
\hline Don't know & 64 & 27.59 \\
\hline \multicolumn{3}{|l|}{ Fatigue } \\
\hline Associated & 200 & 86.21 \\
\hline Not associated & 16 & 6.9 \\
\hline Don't & 16 & 6.9 \\
\hline \multicolumn{3}{|l|}{ Cough } \\
\hline Associated & 216 & 93.1 \\
\hline Not associated & - & - \\
\hline I don't know & 16 & 6.9 \\
\hline \multicolumn{3}{|c|}{ Spontaneous hemorrhage } \\
\hline Associated & 32 & 13.79 \\
\hline Not associated & 96 & 41.38 \\
\hline I don't know & 104 & 44.83 \\
\hline
\end{tabular}




\begin{tabular}{|lcc|}
\hline Skin rash & 36 & 15.52 \\
\hline Associated & 96 & 41.38 \\
\hline Not associated & 100 & 43.10 \\
\hline Don't know & & \\
\hline Shortness of breath & 208 & 89.66 \\
\hline Associated & 8 & 3.45 \\
\hline Not associated & 16 & 6.9 \\
\hline Don't know & & \\
\hline Overall Knowledge towards CoVID-19 & 36 & 15.52 \\
\hline Poor COVID-19 knowledge & 152 & $\mathbf{6 5 . 5 2 ^ { \xi }}$ \\
\hline Moderate COVID-19 knowledge & 44 & 18.97 \\
\hline Good COVID-19 knowledge & & \\
\hline
\end{tabular}

* Frequency of missing value that doesn't tally. ${ }^{\xi}$ The Overall knowledge assessment score was $65.52 \%$, ranked as "moderate"

\section{Attitude toward health COVID-19 health seeking}

In this paper, we assessed attitude of participants towards COVID19 and associated health seeking behaviours. The majority of participants $(82.76 \%)$ had not contracted COVID19 before this survey (figure 2). More than half of participants (58.62\%) were willing to test for COVID19 voluntarily. All participants showed readiness to seek medical care from a hospital for treatment of other diseases despite the COVID19 preventive measures in place. Regarding isolation if they contracted COVID19, 156 (67.24\%) of the participants preferred hospital isolation to home isolation (Table 3). Most of the participants $(n=136$, $58.62 \%$ ) had a neutral attitude towards COVID-19 health-seeking. Most important reasons for vaccination hesitancy were unknown safety of the vaccines $(17.4 \%)$ and unknown long term effects of the vaccines (18.97\%). Nearly a third (27.59\%) of the participants declared to have no intention to get vaccinated whatsoever.

Table 3: Attitude toward COVID-19 health seeking $n=232$ 
Are you willing to do a voluntary test for COVID 19 ?

Yes

No

96

41.38

If you have another disease other than COVID 19, will you go to the hospital?

Yes
No
If you were tested positive for COVID-19, would you prefer to be isolated in the
house or hospital for your medical care?

House

72

31.03

Hospital

156

67.24

I don't know

4

1.72

Attitude toward COVID-19 health seeking

Negative attitude

96.41

41.38

Neutral

136

58.62

\section{COVID-19 prevention practices}

Results presented in Table 4 indicate that most of the participants had good COVID-19 prevention practices by 114 (49.14\%) of the participants showed to accept and practice prescribed preventive measures. The most commonly adopted preventive practice was "hand sanitization", adopted by all participants. To prevent COVID-19, 224 participants (96.55\%) practiced "physical distancing", whereas $216(93.10 \%)$ wore "face masks". Participants who reported to practice "Confinement" were 212 or $91.38 \%$ of those interviewed.

Table 4: COVID-19 prevention practices 
Practice

N $\%$

What are the measures you are currently taking to prevent this illness?

Physical distancing

\begin{tabular}{lll} 
Yes & 224 & 96.55 \\
\hline No & 8 & 3.45 \\
\hline Use of mask & 216 & 93.10 \\
\hline Yes & 16 & 6.9 \\
\hline No & & \\
\hline Washing hands using sanitizer & 232 & 100 \\
\hline Yes & - & - \\
\hline No & & \\
\hline Confinement & 20 & 8.62 \\
\hline Yes & 212 & 91.38 \\
\hline No & & \\
\hline Use of traditional remedies & 124 & 53.45 \\
\hline Yes & 108 & 46.55 \\
\hline No & & \\
\hline No measures taken & 110 & 47.41 \\
\hline Yes & 49.14 & 1.72 \\
\hline No & 228 & 98.28 \\
\hline CoVID-19 Prevention practices & & \\
\hline Poor preventive practice & 8.45 \\
\hline Moderate preventive practice & 114 \\
\hline Good preventive practice & & \\
\hline
\end{tabular}

\section{Knowledge and attitude to COVID19 vaccine}

One hundred and fifty-two (65.52\%) of interviewed participants had a negative attitude towards COVID19 vaccines. One hundred and ninety six (84.48\%) of participants acknowledged the presence of a COVID19 vaccine in Tanzania. Despite this knowledge, only 84 (36.21\%) of the participants were willing to be 
vaccinated with fear of unknown long term effects among $18.97 \%$ of participants, whereas only 16 $(6.9 \%)$ were vaccinated against COVID19. The overall attitude towards COVID19 vaccination was reported to be negative (Table 5).

Table 5: Attitude towards COVID-19 vaccine 
Attitude

$\mathbf{N}$

$\%$

There is a vaccine against COVID-19

True

196

84.48

False

24

10.34

I don't know

12

5.17

Do you know that an approved vaccine is available in Tanzania?

\begin{tabular}{lll}
\hline Yes & 184 & 79.31 \\
\hline No & 16 & 6.9 \\
\hline I don't know & 32 & 13.79 \\
\hline Are you prepared to be vaccinated with the vaccine & & \\
\hline Yes & 84 & 36.21 \\
\hline No & 148 & 63.79 \\
\hline Reasons for not being prepared & & \\
\hline Its safety is unknown & 40 & 17.24 \\
\hline Long term side effects unknown & 44 & 18.97 \\
\hline Has serious side effects & 24 & 10.34 \\
\hline Prefer natural immunity & 20 & 8.62 \\
\hline Undecided for now & 32 & 13.79 \\
\hline I have no intention to be vaccinated at & 64 & 27.59 \\
\hline Do not know & 8 & 3.45 \\
\hline
\end{tabular}

Have you been vaccinated against COVID-19?

Yes

16

6.90

No

216

93.10

Attitude towards COVID-19 vaccine

$\begin{array}{lll}\text { Negative attitude } & 152 & 65.52 \\ \text { Neutral attitude } & 64 & 27.59 \\ \text { Positive attitude } & 16 & 6.90\end{array}$




\section{Factors associated with COVID-19 vaccine hesitancy}

A chi-square test was performed to understand the factors that were associated with observed knowledge, attitude and practices towards COVID19 and COVID19 vaccines. Fisher's exact test was used to provide the significant results of the variables. A p-value of $<0.05$ was selected to show statistical significance of the associations. Gender, education level, participant occupation, work environment, workplace crowdedness, and COVID19 knowledge were all found to be linked with vaccine hesitancy $(p<0.05)$ (Table 6 \& Figure 3). Male gender, least education level, for occupation: teachers, health care workers and students, showed the highest level of COVID19 vaccine hesitancy. In addition, poor knowledge on COVID19 was an important factor for vaccine hesitancy whereby only $16.67 \%$ of participants with poor COVID19 knowledge compared to $39.5 \%$ and $9.09 \%$ of those who showed moderate and good knowledge, had positive attitude to COVID19 vaccination (Chi-20.06, $p=0.001$ ). Consistently, participants who showed poor COVID19 preventive practices were the most hesitant to vaccination against COVID19 (Chi=5.42, $\mathrm{p}=0.03)$.

Table 6: Factors associated with COVID-19 vaccine hesitancy 
Variable

Total

ATTITUDE TOWARDS

COVID-19 VACCINE

$n(\%) \quad-V e, n(\%) \quad$ Neutral $\quad+$ Ve, $n(\%)$

\section{Age category}

$\begin{array}{lllllll}15-24 & 48 & 34 & 12 & 2(4.17) & 2.2025 & 0.671^{*} \\ & (20.69) & (70.83) & (25.00) & & & \\ 25-34 & 80 & 54 & 22 & 4(5.50) & & \\ & (34.48) & (67.50) & (27.50) & & & \\ 35+ & 104 & 64 & 30 & 10(9.62) & \\ & (44.83) & (61.54) & (28.85) & & \end{array}$

\section{Gender}

Male

Female

Educational level

Primary education

Secondary education

Vocational education

University education

\section{Profession}

Teacher

Peasant

Trader

Doctor/Nurse

Drivers

Students
168

(72.41)

$\begin{array}{llll}64 & 32 & 28 & 4(6.25) \\ (27.59) & (50.00) & (43.75) & \end{array}$

$12(7.14) \quad 11.67 \quad 0.003^{*}$

36

(21.43)

28
$(43.75)$

$\begin{array}{lll}80 & 60 & 12 \\ (34.48) & (75.00) & (15.00)\end{array}$

$\begin{array}{lll}80 & 60 & 12 \\ (34.48) & (75.00) & (15.00)\end{array}$

$8(10.00) \quad 24.47<0.001^{*}$

$\begin{array}{lll}84 & 60 & 20 \\ (36.21) & (71.43) & (23.81)\end{array}$

$4(4.76)$

$\begin{array}{llll}28 & 16 & 12 & 0(0.00) \\ (12.07) & (57.14) & (42.86) & \end{array}$

$\begin{array}{lll}40 & 12 & 20 \\ (17.24) & (40.00) & (50.00)\end{array}$

$4(10.00)$

$(17.24) \quad(40.00) \quad(50.00)$ 
Other

$$
\begin{array}{llll}
60 & 36 & 20 & 4(6.67) \\
(25.86) & (60.00) & (33.33) &
\end{array}
$$

\section{Working environment}

Hospital/Health care

$\begin{array}{llllll}16 & 12 & 4 & 0(0.00) & 36.48 & <0.001 \\ (6.90) & (75.00) & (25.00) & & & \end{array}$

School

$\begin{array}{llll}50 & 24 & 26 & 0(0.00) \\ (21.55) & (48.00) & (52.00) & \end{array}$

Market

$\begin{array}{llll}52 & 38 & 10 & 4(7.69) \\ (22.41) & (73.08) & (19.23) & \end{array}$

Town center

$\begin{array}{llll}46 & 34 & 4(8.70) & 8(17.39)\end{array}$

Home

28

20

$\begin{array}{ll}20 & 8 \\ (71.43) & (28.57)\end{array}$

Others

$\begin{array}{llll}40 & 24 & 12 & 4(10.00) \\ (17.24) & (60.00) & (30.00) & \end{array}$

\section{Levels of crowdedness of} workplace

\begin{tabular}{lllllll} 
Very crowded & $\begin{array}{l}8 \\
(37.93)\end{array}$ & $\begin{array}{l}60 \\
(68.18)\end{array}$ & $\begin{array}{l}20 \\
(22.73)\end{array}$ & $8(9.09)$ & 21.18 & $0.002^{*}$ \\
\hline Moderately & 108 & 68 & 32 & $8(7.41)$ & \\
& $(46.55)$ & $(62.96)$ & $(29.63)$ & \\
Least crowded & 16 & 16 & $0(0.00)$ & $0(0.00)$ \\
& $(6.90)$ & $(100.00)$ & & \\
\hline Isolated & 20 & $8(40.00)$ & $\begin{array}{l}12 \\
(60.00)\end{array}$ & $0(0.00)$
\end{tabular}

Income reduction due to COVID-19

\begin{tabular}{|c|c|c|c|c|c|c|}
\hline No & $\begin{array}{l}168 \\
(72.41)\end{array}$ & $\begin{array}{l}108 \\
(64.29)\end{array}$ & $\begin{array}{l}52 \\
(30.95)\end{array}$ & $8(4.76)$ & 8.81 & 0.083 \\
\hline $\begin{array}{l}\text { Yes, I lost my job/had salary } \\
\text { reduction due to quarantine }\end{array}$ & $\begin{array}{l}4 \\
(1.72)\end{array}$ & $\begin{array}{l}4 \\
(100.00)\end{array}$ & $0(0.00)$ & $0(0.00)$ & & \\
\hline $\begin{array}{l}\text { Yes, I lost my job/had salary } \\
\text { reduction due to restriction }\end{array}$ & $\begin{array}{l}60 \\
(25.86)\end{array}$ & $\begin{array}{l}40 \\
(66.67)\end{array}$ & $\begin{array}{l}12 \\
(20.00)\end{array}$ & 8 (13.33) & & \\
\hline
\end{tabular}

\section{Knowledge towards COVID-19}

$\begin{array}{lllllll}\text { Poor } & 36 & 24 & 6 & 6(16.67) & 20.06 & <0.001^{*} \\ \text { Moderate } & (15.52) & (66.67) & (16.67) & & \\ & 152 & 92 & 54 & 6(3.95) & \\ \text { Good } & (65.52) & (60.53) & (35.53) & \\ & 44 & 36 & 4(9.09) & 4(9.09) \\ & & & \end{array}$


COVID-19 prevention practices

\begin{tabular}{lllllll}
\hline Poor & 8 & 8 & $0(0.00)$ & $0(0.00)$ & 5.42 & $0.029 *$ \\
\hline Moderate & $(3.45)$ & $(100.00)$ & & & & \\
& 110 & 74 & 28 & $8(7.27)$ & & \\
\hline Good & $(47.41)$ & $(67.27)$ & $(25.45)$ & & \\
& 114 & 70 & 36 & & \\
& $(49.14)$ & $(61.40)$ & $(31.58)$ & $1 .(7.02)$ & \\
\hline
\end{tabular}

*Fisher's exact test

\section{Discussion}

This is among the first studies that report on the knowledge, attitudes and practices on COVID-19 in Tanzania. Ahead of most other studies, this study has also investigated factors for COVID-19 vaccination hesitancy among one of the Tanzanian regions most hit by COVOD-19, Kilimanjaro region. In the current study, majority of respondents heard about COVID-19 between January and March 2020, indicating a timely awareness of the pandemic in Tanzania. Our findings indicate the combination of social media, news media and news papers as the strongest sources of information regarding COVID-19, reaching to $34.48 \%$ of population as represented by interviewed participants. During epidemics, effective communication is frequently a critical component of health crisis response. Attempts to connect with the public can take several forms and come from a variety of sources. Given the proliferation of smartphones and the rising worldwide availability and distribution of the internet, social media has become a significant communication channel for communicating health emergencies[22], alleviating challenges of public health communication through its affordances and functionality [23]. Mobile phone use has also increased the rate at which behavioural change information concerning epidemics is disseminated [24].

In line with other studies conducted in Tanzania[25], findings in this study show that social media platforms are an effective way in spreading health-awareness information about COVID-19. Furthermore, while social media use serves as an efficient means of communication during a pandemics, alternative ways need to be in place for those with limited internet access. We report that $32.76 \%$ of the respondents in this study heard about COVID191 through newspapers. During a pandemic, reliable and timely communication has been stressed as key to success of any control measures that involve the public [26]. Beyond the requirement for timely information, there is a need for robust and credible health communication channels, which citizens can trust, rely on, and act on. This is where traditional media such as newspapers becomes a helpful public realm in terms of engaging with the audience and discussing the path forward in terms of progress made, problems encountered, and plans in place to beat the virus with concerned members of the public. 
When participants were interviewed for their knowledge on the basic symptoms of COVID19, a moderate knowledge was observed. Of interest was the response to the question of whether SARS COV2, the virus that causes COVID19 was natural or man-made where nearly half of the respondents (48.3\%) said it was man-made whereas $36.21 \%$ did not know whether it was man-made or natural. Tanzania and other African countries have been working to increase awareness and provide information to the public through various channels of communication (eg, radio, television advertisements, public health messages by prominent celebrities and national leaders, pamphlets and signboards at public places) about mode of infection, symptoms, and infection control measures. However, misinformation about COVID-19 remains intact in these countries.

As previously reported by other studies [27], misinformation about COVID19 is a significant barrier to global public health since it may inadvertently aggravate public health challenges by indirectly facilitating increased disease transmission [28]. It is unfortunate that most social media has been flooded with information regarding the origin and implications of the disease while much of the information about COVID19 its symptoms, transmission routes, and response mechanisms have been largely unreliable [29-32]. Despite this knowledge and best preventive practices observed in the current study, a considerable proportion of the participants believed the virus was man-made, with evil intentions against targeted communities. Our findings that only $6.9 \%$ of the participants were vaccinated against COVID19 largely explain the basis of the vaccination hesitance.

Overall, our study found a high proportion of COVID19 vaccine reluctance of approximately 65 percent. When participant characteristics for vaccine reluctance were examined, male gender, participants with the least education, and occupation (teachers, health care workers, and students) were shown to be more apprehensive to vaccination. Our findings are both similar and dissimilar to those of other studies. For example, contrary to our findings, a study in the United States found that vaccine hesitancy was higher in females than in males, but when it came to education, the least educated participants were more likely to be hesitant about COVID19 vaccination than those with at least a bachelor's degree[33-35]. In this study, healthcare workers (HCWs) were unwilling to get COVID19 immunization. Although the participants correctly judged the severity, prevention, and safety of the COVID-19 vaccine, they were generally hesitant or refused to be vaccinated [35]; [9-12]. $\mathrm{VH}$ among HCWs poses a serious danger to pandemic-control strategies.

\section{Conclusion}

We report intermediate understanding of COVID19, as well as effective preventive practices, but negative attitudes toward COVID19 vaccination, which has resulted in low vaccination rates. Misinformation about COVID19 appears to be a factor in vaccine hesitancy. COVID-19 vaccination apprehension must be understood in the context of the interaction between misinformation dissemination and accompanying emotional reactions. Because social media and newspapers are effective conduits for health campaigns, vaccination programs should provide a focused, localized, and sympathetic response to misinformation. 


\section{Declarations}

Author contribution

$\mathrm{JC}$ designed the study and wrote the manuscript. KR analysed and interpreted data. OB participated in questionnaire validation and data collection. HS made critical reviews of the manuscript. EK designed the study, developed the questionnaire and made critical review of the manuscript.

\section{Acknowledgements}

We acknowledge all participants who consented to participate in the survey

\section{Funding}

No funding was made to this study

\section{Data Sharing Statement}

All data generated or analyzed during this study are included in this published article.

\section{Ethics Approval and Consent to Participate}

This study was conducted after the approval of the Kilimanjaro Christian Medical University College (KCMUCo) Research and Ethics Committee (Certificate \#2419). Permission to conduct the study was also obtained from Kilimanjaro Regional and District Administrative Secretaries and District Medical Officer. After an explanation of the study aims and procedures to the study prospective participants, individuals were asked to voluntarily agree to participate in the study. All authors hereby declare that all procedures in this study were performed in accordance with the ethical standards laid down in the 1964 Declaration of Helsinki.

\section{Author Contributions}

\section{Disclosure}

The authors have no conflicts of interest to declare.

\section{References}

1. Olson O, Berry C, Kumar N: Addressing parental vaccine hesitancy towards childhood vaccines in the United States: a systematic literature review of communication interventions and strategies. Vaccines 2020, 8: 590.

2. Dub+® $E$, Gagnon $D$, Ouakki $M$, Bettinger JA, Guay $M$, Halperin $S$ et al:: Understanding vaccine hesitancy in Canada: results of a consultation study by the Canadian Immunization Research Network. PloS one 2016, 11: e0156118. 
3. Cooper S, Betsch C, Sambala EZ, Mchiza N, Wiysonge CS: Vaccine hesitancyGÇôa potential threat to the achievements of vaccination programmes in Africa. Human vaccines \& immunotherapeutics 2018, 14: 2355-2357.

4. National Academies of Sciences EaM. Strategies for building confidence in the COVID-19 Vaccines. 2021. Washington, DC: The National Academies Press. doi. org/10.17226/26068. Ref Type: Generic

5. Lancet T: Access to COVID-19 vaccines: looking beyond COVAX. Lancet (London, England) 2021, 397: 941.

6. Eaton L. Covid-19: WHO warns against GÇ£vaccine nationalismGÇø or face further virus mutations. 2021. British Medical Journal Publishing Group.

Ref Type: Generic

7. World Health Organization. Data for action: achieving high uptake of COVID-19 vaccines: gathering and using data on the behavioural and social drivers of vaccination: a guidebook for immunization programmes and implementing partners: interim guidance, 1 April 2021. 2021. World Health Organization.

Ref Type: Report

8. Wiyeh AB, Cooper S, Nnaji CA, Wiysonge CS: Vaccine hesitancy GÇÿoutbreaksGÇö: using epidemiological modeling of the spread of ideas to understand the effects of vaccine related events on vaccine hesitancy. Expert review of vaccines 2018, 17: 1063-1070.

9. Murphy J, Valli+¿res F, Bentall RP, Shevlin M, McBride O, Hartman TK. Psychological characteristics associated with COVID-19 vaccine hesitancy and resistance in Ireland and the United Kingdom. Nat Commun 12, 29 (2021). 2021.

Ref Type: Generic

10. Fisher KA, Bloomstone SJ, Walder J, Crawford S, Fouayzi H, Mazor KM: Attitudes toward a potential SARS-CoV-2 vaccine: a survey of US adults. Annals of internal medicine 2020, 173: 964-973.

11. Neumann-B+Âhme S, Varghese NE, Sabat I, Barros PP, Brouwer W, van Exel J et al:: Once we have it, will we use it. A European survey on willingness to b e vaccinated against COVID-19 Springer 2020.

12. Lazarus JV, Ratzan S, Palayew A, Billari FC, Binagwaho A, Kimball S et al.: COVID-SCORE: a global survey to assess public perceptions of government responses to COVID-19 (COVID-SCORE-10). PloS one 2020, 15: e0240011.

13. Sallam M: COVID-19 Vaccine Hesitancy Worldwide: A Concise Systematic Review of Vaccine Acceptance Rates. 2021, 9. 
14. Khubchandani J, Sharma S, Price JH, Wiblishauser MJ, Sharma M, Webb FJ: COVID-19 Vaccination Hesitancy in the United States: A Rapid National Assessment. Journal of Community Health 2021, 46: 270-277.

15. Cardenas NC: GÇÿEurope and United States vaccine hesitancyGÇÖ: leveraging strategic policy for GÇÿlnfodemicGÇÖon COVID-19 vaccines. Journal of Public Health (Oxford, England) 2021.

16. Le Polain de Waroux O, Schellenberg JRA, Manzi F, Mrisho M, Shirima K, Mshinda $\mathrm{H}$ et al:: Timeliness and completeness of vaccination and risk factors for low and late vaccine uptake in young children living in rural southern Tanzania. International health 2013, 5: 139-147.

17. Aaron D, Nagu TJ, Rwegasha J, Komba E: Hepatitis B vaccination coverage among healthcare workers at national hospital in Tanzania: how much, who and why? BMC infectious diseases 2017, 17: 17.

18. Vasudevan L, Baumgartner JN, Moses S, Ngadaya E, Mfinanga SG, Ostermann J: Parental concerns and uptake of childhood vaccines in rural TanzaniaGÇôa mixed methods study. BMC public health 2020, 20: 1-11.

19. Feleke BT, Wale MZ, Yirsaw MT: Knowledge, attitude and preventive practice towards COVID-19 and associated factors among outpatient service visitors at Debre Markos compressive specialized hospital, north-west Ethiopia, 2020. Plos one 2021, 16: e0251708.

20. Seid MA, Hussen MS: Knowledge and attitude towards antimicrobial resistance among final year undergraduate paramedical students at University of Gondar, Ethiopia. BMC infectious diseases 2018, 18: $1-8$.

21. Feleke BT, Wale MZ, Yirsaw MT: Knowledge, attitude and preventive practice towards COVID-19 and associated factors among outpatient service visitors at Debre Markos compressive specialized hospital, north-west Ethiopia, 2020. Plos one 2021, 16: e0251708.

22. Yu M, Li Z: Yu, z., He, J., \& Zhou, J.(2020). Communication related health crisis on social media: A case of COVID-19 outbreak. Current Issues in Tourism 1-7.

23. Schillinger D, Chittamuru D, Ram+jrez AS: From GÇ£infodemicsGÇØ to health promotion: a novel framework for the role of social media in public health. American journal of public health 2020, 110: 1393-1396.

24. Dong M, Zheng J: Letter to the editor: Headline stress disorder caused by Netnews during the outbreak of COVIDGÇÉ19. Health expectations: an international journal of public participation in health care and health policy 2020, 23: 259.

25. Khamis RM, Geng Y: Social media usage in health communication and its implications on public health security: A case study of Covid-19 in Zanzibar. Online Journal of Communication and Media 
Technologies 2021, 11: e202101.

26. Manganello J, Bleakley A, Schumacher P: Pandemics and PSAs: Rapidly changing information in a new media landscape. Health Communication 2020, 35: 1711-1714.

27. Osuagwu UL, Miner CA, Bhattarai D, Mashige KP, Oloruntoba R, Abu EK et al:: Misinformation about COVID-19 in sub-saharan africa: Evidence from a cross-sectional survey. Health security 2021, 19: 44-56.

28. El Sayed MJ: Beirut Ammonium Nitrate Explosion: A Man-Made Disaster in Times of the COVID19 Pandemic. Disaster medicine and public health preparedness 2020, 1-5.

29. Palade I, Balaban DC: An Analysis of COVID-19-Related Fake News from Romania. A Pilot Qualitative Study. Journal of Media Research 2020, 13.

30. Jelnov P. Confronting Covid-19 myths: Morbidity and mortality. 2020. GLO Discussion Paper. Ref Type: Report

31. Sahoo S, Padhy SK, Ipsita J, Mehra A, Grover S: Demystifying the myths about COVID-19 infection and its societal importance. Asian journal of psychiatry 2020, 54: 102244.

32. Amgain K, Neupane S, Panthi L, Thapaliya P: Myths versus truths regarding the novel coronavirus disease (COVID-2019) outbreak. Journal of Karnali Academy of Health Sciences 2020, 3.

33. Liu R, Li GM: Hesitancy in the time of coronavirus: Temporal, spatial, and sociodemographic variations in COVID-19 vaccine hesitancy. SSM-population health 2021, 15: 100896.

34. Soares P, Rocha JV, Moniz M, Gama A, Laires PA, Pedro AR et al.: Factors associated with COVID19 vaccine hesitancy. Vaccines 2021, 9: 300.

35. Aw J, Seng JJB, Seah SSY, Low LL: COVID-19 vaccine hesitancyGÇöA scoping review of literature in high-income countries. Vaccines 2021, 9: 900.

\section{Figures}




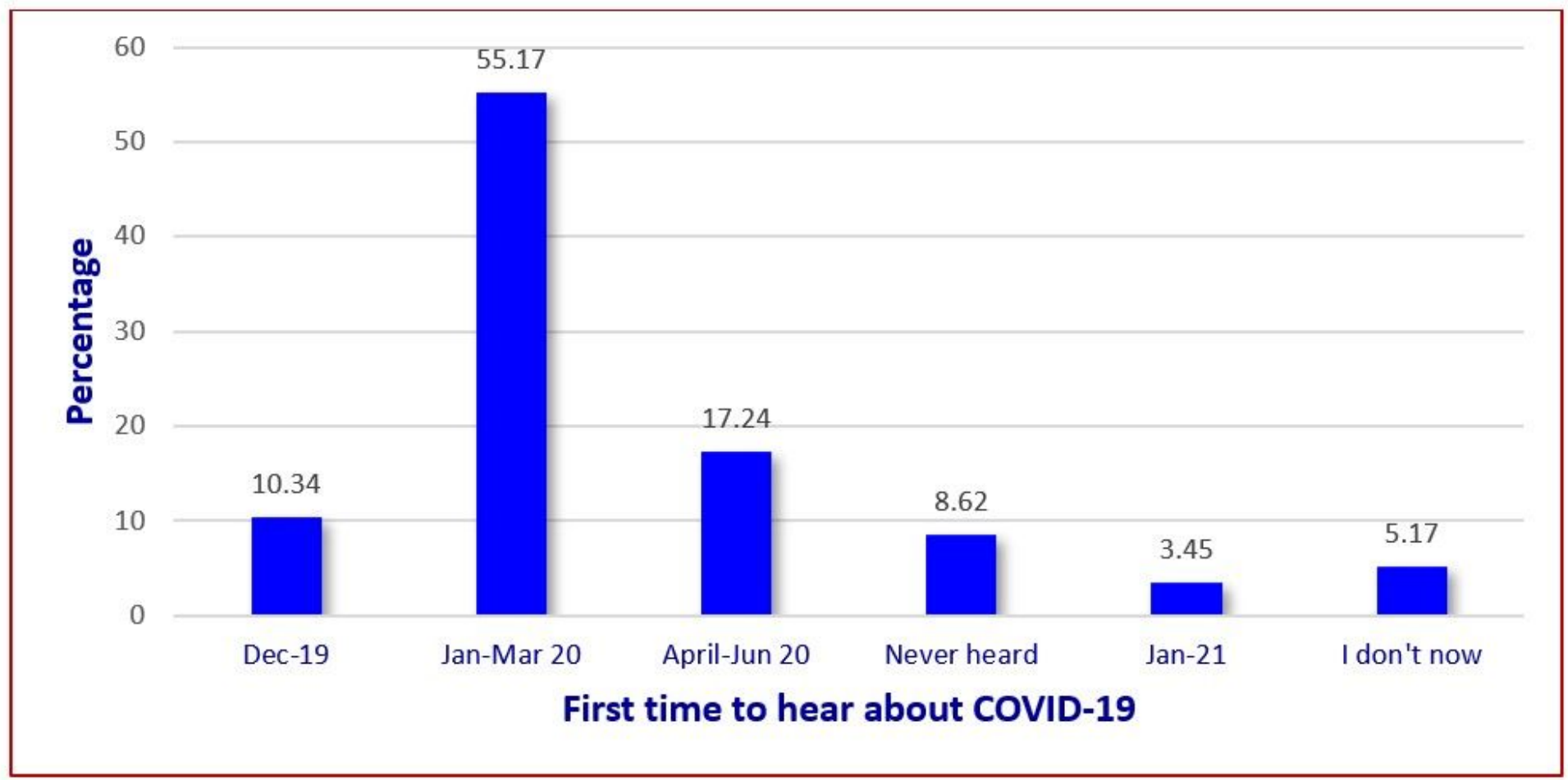

Figure 1

Percentage distribution on participant's first time to hear about COVID-19 (n=232)

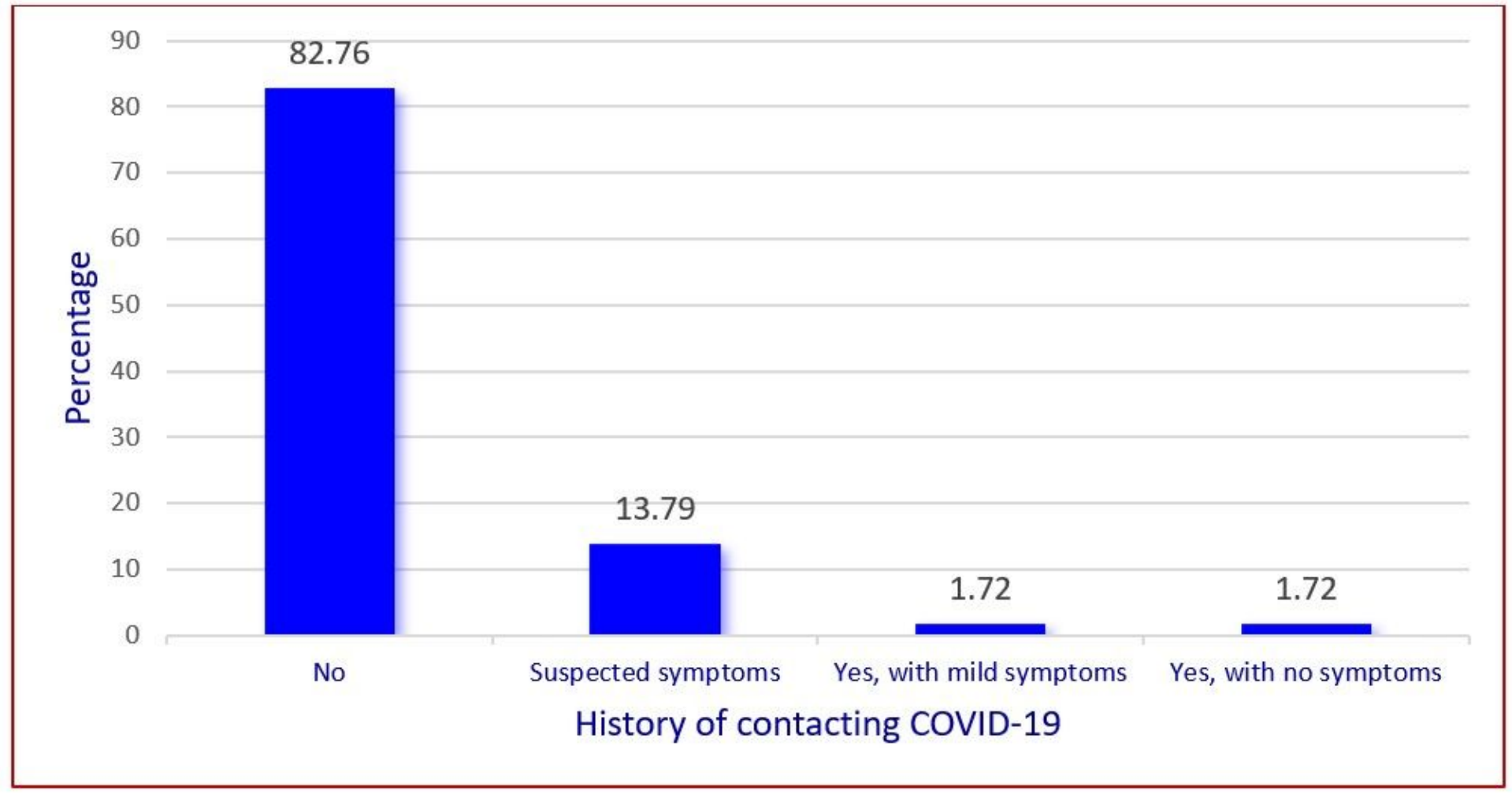

Figure 2

Percentage distribution on Respondents source of information about COVID-19 (n=232) 


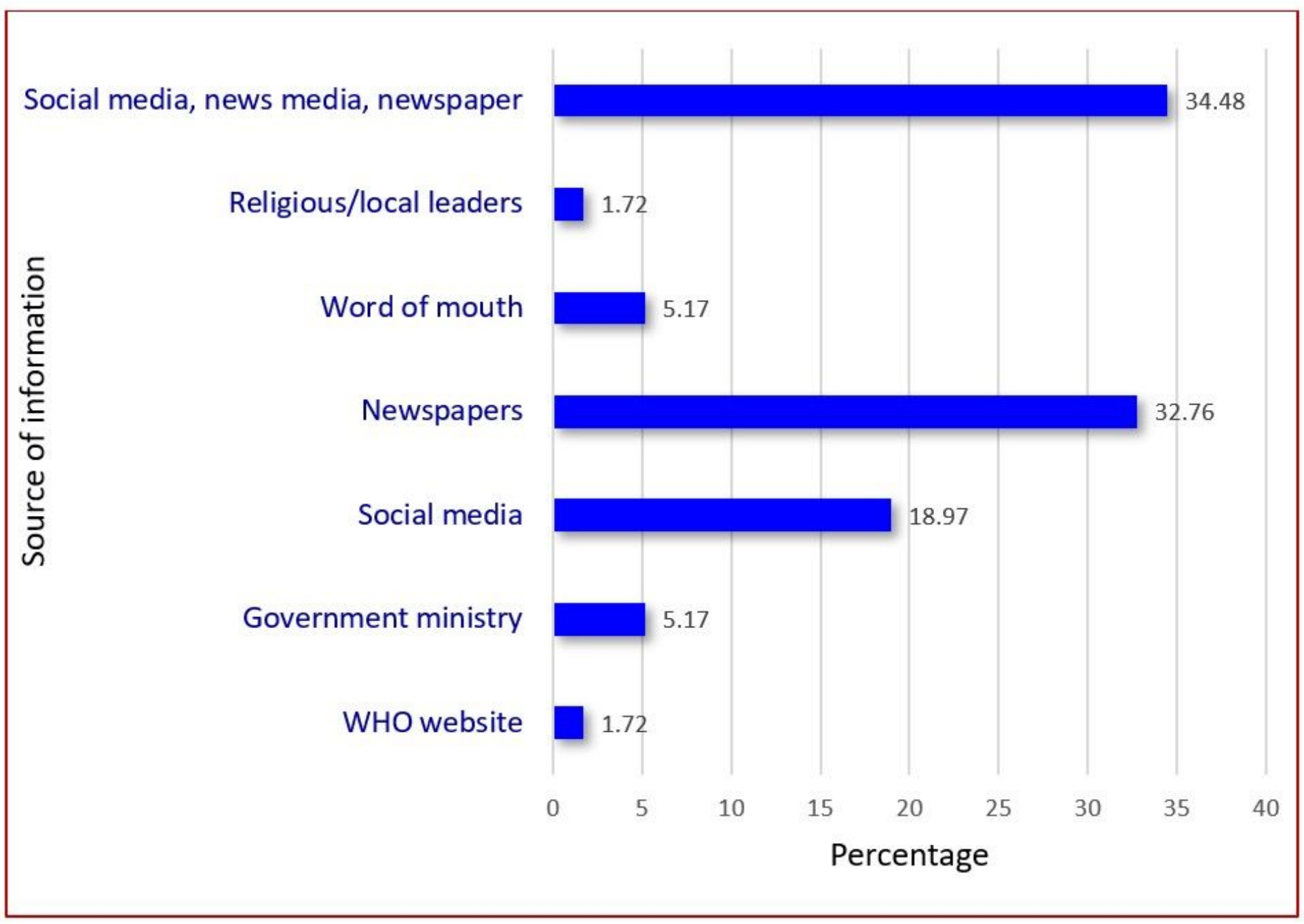

Figure 3

Fig. 2 History of contracting COVID-19 : Percentage distribution of history of contacting COVID-19 ( $n=$ 232) 


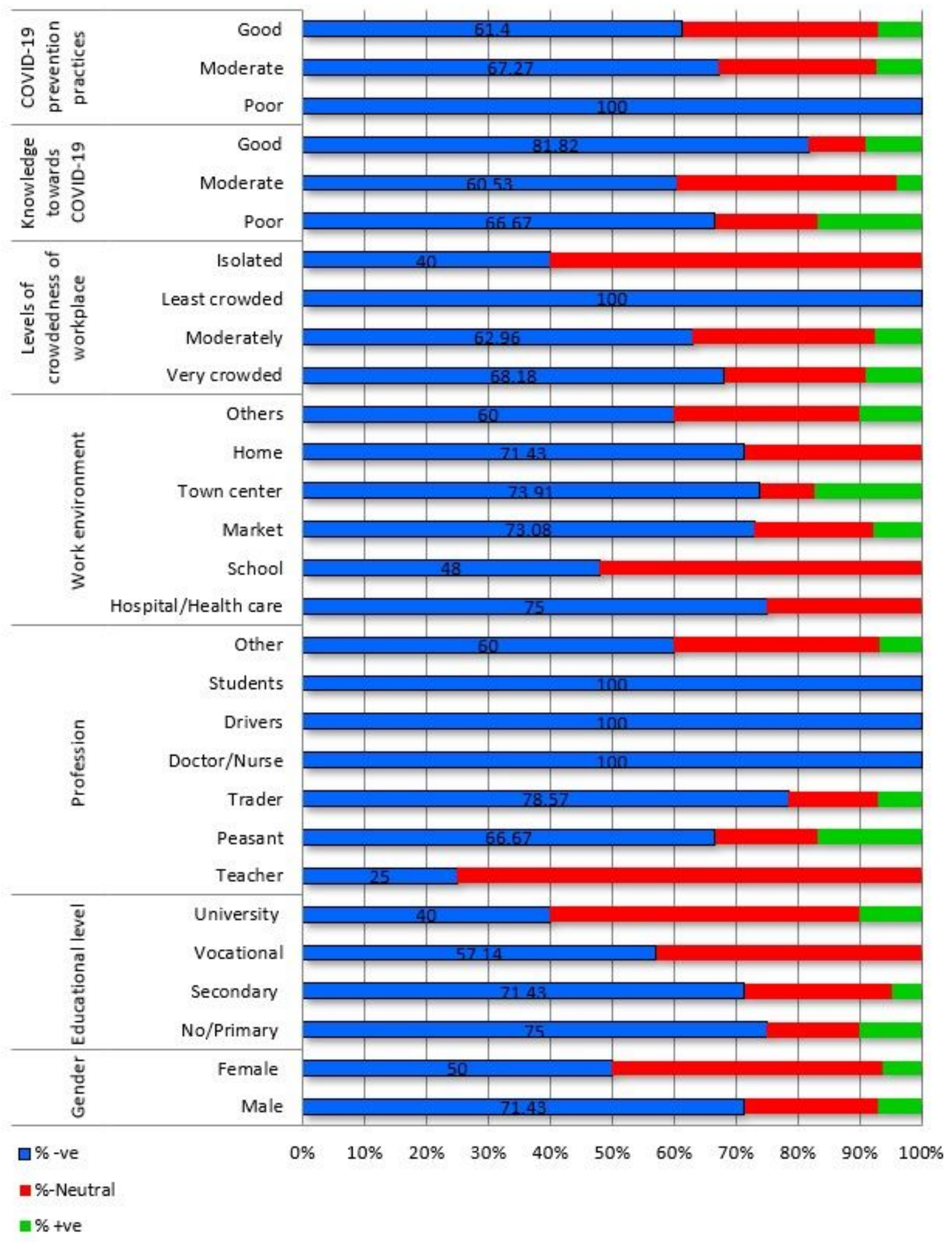

Figure 4

Figure 3: Significant Factors associated with COVID-19 Vaccine Hesitancy 